\title{
The Hawthorne effect in the measurement of adolescent smoking
}

\author{
M MURRAY*, A V SWAN, S KIRYLUK, AND G C CLARKE \\ From the Division of Community Medicine, UMDS, St Thomas's Hospital Medical School, London SE1 7EH; and \\ Centre for Applied Health Studies*, University of Ulster, Coleraine BTS2 ISA, Northern Ireland
}

SUMMARY It is possible that the process of repeatedly measuring the smoking behaviour of adolescents may very well affect that behaviour. This paper reports a test for the extent of such a "Hawthorne" effect in a longitudinal survey of smoking by English adolescents. The self-reported smoking behaviour of 15-16 year olds who attended schools which had participated in the study for five years was compared with that of 15-16 year olds who attended other schools. The prevalence of smoking was lower in those schools which had been surveyed for five years. A number of possible explanations for this finding are discussed. It is concluded that such a "Hawthorne" effect is unlikely to bias analyses relying on comparisons within the data set. However, they can certainly bias the prevalance estimates obtained from such a study. Thus they provide yet another reason why? prevalence estimates from cohorts studied over a period of time must be used with considerable caution.

One difficulty in conducting social scientific research is that the actual investigation itself may influence the behaviour of the individuals under observation. This phenomenon is often termed the "Hawthorne" effect after a study of productivity conducted in the Hawthorne Plant of the Western Electric Company in America during the 1920 s. $^{1}$ There it was supposedly found that merely observing the workers was sufficient to affect their productivity. Although recently ${ }^{2}$ the details of this study have been criticised, the Hawthorne effect is still generally accepted as a description of the phenomenon that the mere observation or measurement of behaviour may alter it.

The information obtained in the MRC/Derbyshire Smoking Study ${ }^{3}$ which involved repeated questioning of a large sample of adolescents could well have been subject to such a Hawthorne effect. This paper reports the findings of a section of that study designed to assess the extent of any such Hawthorne effect on the self-reported smoking behaviour of adolescents.

\section{Methods}

Table 1 details the basic design of the MRC/Derbyshire Smoking Study. A cohort of approximately 6000 adolescents who attended any one of 48 randomly selected secondary schools in Derbyshire, England were followed from 1974 when they were aged 11-12 years until they reached school-leaving age in 1978. Each year while they were at school this study group of adolescents answered a questionnaire in their classrooms under the supervision of their teachers. This questionnaire requested details of the adolescents' smoking practices, social activities and attitudes towards various issues.

Table 1 Design of MRC/Derbyshire Study

\begin{tabular}{|c|c|c|c|c|c|c|}
\hline Year & & 1974 & 1975 & 1976 & 1977 & 1978 \\
\hline Age & $\begin{array}{l}11-12 \mathrm{yrs} \\
12-13 \mathrm{yrs} \\
13-14 \mathrm{yrs} \\
14-15 \\
15-16 \mathrm{yrs}\end{array}$ & SG & SG & SG & SG & $\begin{array}{l}\text { SG } \\
\text { CG }\end{array}$ \\
\hline
\end{tabular}

SG Study group children, CG Control group children

To test for the effect of repeated questioning on the study group adolescents' self-reported smoking behaviour their replies in 1978 were contrasted with those of a control group of 15-16 year olds who were only questioned in that year. These control adolescents were obtained from 20 randomly selected Derbyshire secondary schools which were not included in the study sample. These schools were only approached in 1978 when their 15-16 year olds were required to answer a questionnaire about their current 
smoking practices. In total, adequate data were obtained from 1934 individuals in the control group and from 5616 in the study group.

Regression techniques using log-linear modelling for contingency tables ${ }^{4}$ were used to analyse the distribution of individuals among the smoking categories.

\section{Results}

The response rate to the questionnaires by the adolescents was calculated from the class teachers' replies to a short administrative form requesting details of class size and absenteeism. Unfortunately the teachers in eight of the control schools did not adequately complete these forms. In the remaining twelve control schools the response rate reached $84 \%$. In the study group schools the response rate in 1978 was $75 \%$. This difference in response rate reached statistical significance $\left(\chi^{2}=48 \cdot 3, \mathrm{df}=1, \mathrm{p} \ll 0.01\right)$.

Table 2 gives the self-reported smoking behaviour of the 15-16 year olds who attended the study and control schools in 1978. Significantly more of the girls who attended the control schools than those who attended the study schools smoked cigarettes $\left(\chi^{2}=23.9, \quad \mathrm{df}=3, \quad \mathrm{p}<0.01\right)$. There were slight differences between the boys in the two groups, but they did not reach significance.

Table 2 Prevalence of smoking among 15-16 year olds in 1978 (per cent)

\begin{tabular}{|c|c|c|c|c|}
\hline & \multicolumn{2}{|l|}{ Boys } & \multicolumn{2}{|l|}{ Girls } \\
\hline & $\begin{array}{l}\text { Study } \\
(n=2700)\end{array}$ & $\begin{array}{l}\text { Control } \\
(n=1022)\end{array}$ & $\begin{array}{l}\text { Study } \\
(n=2915)\end{array}$ & $\begin{array}{l}\text { Control } \\
(n=912)\end{array}$ \\
\hline Non-smoker & 24.9 & $26 \cdot 8$ & $29 \cdot 3$ & $22 \cdot 9$ \\
\hline Experimental smoker & 40.6 & $38 \cdot 1$ & $37 \cdot 6$ & $36 \cdot 7$ \\
\hline Occasional smoker & $8 \cdot 7$ & $8 \cdot 1$ & 9.8 & $10 \cdot 1$ \\
\hline Regular smoker & $25 \cdot 8$ & $27 \cdot 0$ & $23 \cdot 3$ & $30 \cdot 3$ \\
\hline
\end{tabular}

Table 3 gives details of the weekly cigarette consumption of the adolescents. The consumption of cigarettes was significantly higher among the control girls than among the study girls $\left(\chi^{2}=16.5, \mathrm{df}=3\right.$, $\mathrm{p}<0.01)$. A similar pattern among boys did not reach significance.

Table 3 Weekly cigarette consumption of 15-16 year olds in 1978 (per cent)

\begin{tabular}{|c|c|c|c|c|}
\hline & \multicolumn{2}{|l|}{ Males } & \multicolumn{2}{|l|}{ Females } \\
\hline & $\begin{array}{l}\text { Study } \\
(n=2592)\end{array}$ & $\begin{array}{l}\text { Control } \\
(n=1019)\end{array}$ & $\begin{array}{l}\text { Study } \\
(n=2870)\end{array}$ & $\begin{array}{l}\text { Control } \\
(n=909)\end{array}$ \\
\hline $\begin{array}{l}\text { None } \\
1-35 \\
36-70 \\
70\end{array}$ & $\begin{array}{r}72.3 \\
13.9 \\
8.4 \\
5.5\end{array}$ & $\begin{array}{r}70.4 \\
14.2 \\
9.4 \\
6.0\end{array}$ & $\begin{array}{r}73 \cdot 3 \\
18 \cdot 0 \\
6 \cdot 2 \\
2 \cdot 4\end{array}$ & $\begin{array}{r}66.8 \\
21.9 \\
7.5 \\
3.9\end{array}$ \\
\hline
\end{tabular}

Table 4 details the brand preferences of those adolescents classified as regular smokers. The vast majority smoked middle tar cigarettes (almost all the cheapest brand). Although there was a slight tendency for the control group smokers to have a greater preference for middle or high tar cigarettes this pattern failed to reach significance for either boys or girls.

Table 4 Cigarette brand preferences of regular smokers (per cent)

\begin{tabular}{lccccc}
\hline & \multicolumn{2}{l}{ Male } & \multicolumn{3}{l}{ Female } \\
\cline { 2 - 3 } \cline { 5 - 6 } & Study & Control & & Study & Control \\
\hline Low tar & 2.1 & 1.6 & & 2.4 & 4.0 \\
Low-middle tar & 2.9 & 3.1 & & 3.9 & 1.5 \\
Middle tar & 93.5 & 93.7 & & 93.3 & 94.2 \\
High tar & 1.5 & 1.6 & & 0.3 & 0.4 \\
\hline
\end{tabular}

Finally table 5 shows the inhalation patterns of the regular smokers. Control boys who smoked always inhaled the cigarette smoke significantly more often than the study boys who smoked $\left(\chi^{2}=7 \cdot 9, \mathrm{df}=2\right.$, $\mathrm{p}<0.05)$. A similar pattern among girls failed to reach significance.

Table 5 Inhalation patterns of regular smokers (per cent)

\begin{tabular}{llllll}
\hline & Male & \multicolumn{3}{l}{ Female } \\
\cline { 2 - 3 } \cline { 5 - 6 } & $\begin{array}{l}\text { Study } \\
(n=682)\end{array}$ & $\begin{array}{l}\text { Control } \\
(n=275)\end{array}$ & $\begin{array}{l}\text { Study } \\
(n=67 I)\end{array}$ & $\begin{array}{l}\text { Control } \\
(n=275)\end{array}$ \\
\hline Never inhales & 4.5 & 4.7 & & 6.4 & 8.0 \\
Inhales sometimes & 23.0 & 14.9 & & 30.3 & 23.6 \\
Always inhales & 72.4 & 80.4 & & 63.3 & 68.4 \\
\hline
\end{tabular}

\section{Discussion}

The results show that in 1978 the general experience of smoking among 15-16 year old girls was less in those schools which had participated in the MRC/ Derbyshire Smoking Study for five years than in a sample of twenty other schools which had not been surveyed before. There was less difference between the boys in these two groups although those who had been surveyed for five years were less likely to inhale if they smoked cigarettes. If these differences represent a genuine effect that could be seen again in surveyed and unsurveyed schools in another place at another time then they can be considered as being due to some sort of Hawthorne effect. Several possible explanations for this can be considered.

Firstly, the difference in the observed smoking behaviour of the two groups may have been due to the different response rates. It may have been that in the study group more smokers than non-smokers failed to answer the questionnaire thus lowering the prevalence 
of smoking apparent in that group. Indeed the lower response rate of the study group potentially involving the smokers more than the non-smokers could be considered as a form of Hawthorne effect involving either the adolescents or their class-teachers reacting against the survey after repeated questionnaires. Secondly, the difference between the two groups could be due to a difference in reportage. The study adolescents may have become quite relaxed about the survey after five years and reported their smoking behaviour truthfully, while the control adolescents, with no commitments to the survey, may have exaggerated their smoking practices. On the other hand the study group may have underestimated their smoking as a result of repeatedly completing questionnaires while the control group did not. Unfortunately, there is no way of distinguishing between those possibilities.

Finally, the difference could reflect a real difference in the behaviour of the two groups that might be termed a substantive Hawthorne effect. This in turn could have occurred for a variety of reasons. Participation in the survey for five years may have alerted the adolescents to the dangers of smoking and so discouraged them. The teachers in the prospective schools and the parents of those adolescents may also have been provoked by the survey to discourage the adolescents from smoking and maybe to stop smoking themselves. The reason why there appears to be a greater effect in the girls may be because of a sex difference in the operation of some or all of the mechanisms previously discussed. Again there is no way of assessing which of these mechanisms occurred or the magnitudes of their relative effects if they did.

A study designed to make it possible to estimate Hawthorne effects unambiguously would need to achieve a response rate approaching $100 \%$. It would also need to ensure that the questionnaire responses were almost completely valid. Both of these are impractical in large longitudinal studies.

In conclusion, the fact that several mechanisms with different implications cannot be distinguished casts doubt on the possibility of estimating and correcting for Hawthorne effects in such studies. If a Hawthorne effect does occur it will bias the estimates of prevalence obtained from the cohort away from the correct values for children of that age and no correction can be deduced. However, the most reliable and hence useful results are those obtained from comparative analyses where like has been compared with like. If the groups to be compared have been surveyed equally, as the sub-groups to be compared within this study group cohort have, then they will be alike with respect to a simple Hawthorne effect so it will not bias the comparisons and can be ignored. A Hawthorne effect that varied to any marked extent from group to group would be very unlikely and almost impossible to cope with in practice so the possibility would have to be ignored.

This study has shown that the Hawthorne effect cannot be estimated unambiguously enough to be used as a bias reducing correction to the prevalence estimates. However, longitudinal studies are inappropriate for estimating prevalences and Hawthorne effects are unlikely to be an important source of bias in internal comparisons.

We wish to thank the pupils and teachers in the schools who participated in this study and the Derbyshire Area Health and County Education Authorities for their co-operation. We would also like to acknowledge the continuing support of Professor W W Holland.

Financial support for this study was provided by the Medical Research Council, the Health Education Council and the Department of Health and Social Security.

Correspondence to: A V Swan, Department of Community Medicine, St Thomas's Hospital Medical School, London SE1 7EH.

\section{References}

${ }^{1}$ Roethlisberger FJ, Dickson WJ. Management and the Worker. Cambridge, Mass.: Harvard University Press, 1939.

2 Carey A. The Hawthorne studies: A radical criticism. Amer Social Rev 1967; 32: 403-16.

${ }^{3}$ Murray M, Swan AV, Bewley BR, Johnson MRD. The development of smoking during adolescence-The MRC/Derbyshire Smoking Study. Inter J Epidem 1983; 12: $185-92$.

${ }^{4}$ Baker RT, Nelder JA. The GLIM Manual for System 3. Oxford: Numerical Algorithms Group, 1978.

Accepted for publication April 1988 